Table 2. Multivariate analyses of BRAF-MDQ and its subscales. ${ }^{*} \mathrm{p}<0.001,{ }^{* *} \mathrm{p}<0.05$ Cells represent beta coefficients with standard error

\begin{tabular}{|c|c|c|c|c|}
\hline & Physical & Living & Cognitive & Emotional \\
\hline Age & $-0.10(0.04)^{\star *}$ & $0.00(0.04)$ & $-0.00(0.03)$ & $0.04(0.02)$ \\
\hline Sex & $-2.65(1.70)$ & $-0.74(1.64)$ & $-1.93(1.26)$ & $-1.21(0.97)$ \\
\hline RF positive & $-3.80(1.15)^{\star *}$ & $-2.85(1.13)^{\star *}$ & & \\
\hline$H A Q \geq 1.1$ & $4.76(1.14)^{\star}$ & $4.05(1.13)^{*}$ & $1.83(0.90)^{\star \star}$ & $1.91(0.70)$ ** \\
\hline Non Anti-TNF & $3.33(1.18)^{* *}$ & $2.60(1.23)^{\star *}$ & & \\
\hline VAS Pain & & & & $0.02(0.01)^{\star *}$ \\
\hline DAS28-ESR & & $1.75(0.65)^{\star \star}$ & & \\
\hline Depression & & & $3.10(1.19)^{\star \star}$ & \\
\hline Good Sleep quality & $-2.75(1.10)^{\star *}$ & & & \\
\hline
\end{tabular}

Disclosure of Interests: None declared

DOI: 10.1136/annrheumdis-2019-eular.7608

\section{AB0321 MORTALITY AND COMPLICATION OF PATIENTS WITH RHEUMATOID ARTHRITIS ADMITTED TO INTENSIVE CARE UNIT IN KYUSHU UNIVERSITY HOSPITAL}

Toshifumi Fujiwara $^{12}$, Yukio Akasaki ${ }^{1}$ Satoshi Ikemura ${ }^{1}$,Jun-Ichi Fukushi ${ }^{1}$, Yasuharu Nakashima1. ' ${ }^{1}$ Kyushu University Hospital, Orthopaedic Surgery, FUKUOKA-SHI, Japan; ${ }^{2}$ Kyushu University Hospital, Emergency and Critical Care Center, FUKUOKA-SHI, Japan

Background: The patients with rheumatoid arthritis (RA) are associated with high mortality caused by comorbidity and complication, and are often required the intensive treatment. Severe infections are among the most common causes of their mortality in intensive care unit $(\mathrm{ICU})^{1) 2}$ ).

Objectives: To determine prognostic factors and mortality in patients with RA, including juvenile idiopathic arthritis (JIA), admitted to the ICU in Kyushu University Hospital, we examined the treatments of RA and JIA, comorbidities, complications, the reasons admitted to the ICU, intensive treatments, mortalities within 30 days, 90 days, and a year.

Methods: Between January 2008 and March 2018, 70 patients (20 males, 50 females) with RA (68) or JIA (2) staying at the ICU of our institution for 48 hours and over were included in this study. The admission to the ICU were performed total 77 of times because 5 patients were readmitted. The average of age and RA duration at the admission was 65.8 \pm 17.7 years $(5-96)$ and $13.5 \pm 14.8$ years $(0-61)$, respectively, and the average of follow-up duration was $879.9 \pm 992.0$ days (3-3988).

Results: The mortality within 30 and 90 days were $21.4 \%(15 / 70)$ and $27.1 \%(19 / 70)$, respectively, and 24 of 65 patients (36.9\%), excluded 5 patients due to the change of hospital, were dead within a year. The reasons for ICU admission included cardiovascular complications (22.9\%), infection $(30.0 \%)$, neurological complications $(7.1 \%)$, respiratory problem $(15.7 \%)$, gastrointestinal problems $(4.3 \%)$, endocrinological cause $(2.9 \%)$, liver problems $(7.1 \%)$, kidney problems $(4.3 \%)$, and others $(5.7 \%)$. The average of ICU length of stay was $7.2 \pm 7.6$ days (2-39). The group of 30 days mortality was significantly higher in the amount of prednisone (8.1 \pm 5.8 vs $4.5 \pm 4.9$ ), Charlson Comorbidity Index3) (5.1 \pm 2.5 vs $2.7 \pm 1.4$ ), and APACHEII4) $(21.7 \pm 9.2$ vs $14.5 \pm 5.5)$ scores. The fatal outcomes within 30 days was mainly caused by infection (46.7\%). In blood data, the low levels of platelet number, total protein, and albumin, and the high levels of creatinine and prothrombin time international normalize ratio at the time of admission of ICU were significantly poorer prognoses.

Conclusion: Our study has shown the high mortality of RA patients admitted to the ICU, and some blood data could be predicted poor prognosis.

\section{REFERENCES}

[1] Moreels M, et al.: Intensive Care Med 2005

[2] Brunnler T, et al.: Intern Med 2015

[3] Quan H, et al.: Am J Epidemiol 2011

[4] Knaus WA, et al.: Crit Care Med 1985

Disclosure of Interests: DOI: 10.1136/annrheumdis-2019-eular.3684

\section{$\mathrm{AB} 0322$}

BIOMASS SMOKE EXPOSURE LINKED TO HIGHER ACPA LEVELS IN MEXICAN-MESTIZO RA-PATIENTS

Dionicio Ángel Galarza-Delgado ${ }^{1}$, Iris Jazmin Colunga-Pedraza ${ }^{1}$, José Ramón Azpiri-López ${ }^{2}$, lleana Cecilia Reynosa-Silva ${ }^{1}$, Raymundo Pineda ${ }^{2}$, Karla Paola Cuéllar-Calderón ${ }^{1}$, Marielva Castro-González ${ }^{1}$, Carolina Marlene MartínezFlores ${ }^{2}$, Alberto Cárdenas ${ }^{1} .{ }^{1}$ Hospital Universitario "Dr. José Eleuterio González", UANL, Rheumatology, Monterrey, Mexico; ${ }^{2}$ Hospital Universitario "Dr. José Eleuterio González", UANL, Cardiology, Monterrey, Mexico

Background: Rheumatoid arthritis (RA) is a chronic, inflammatory, autoimmune disease of the joints. Current classification criteria for RA diagnosis requires the presence of either rheumatoid factor (RF) or anti-citrullinated protein antibodies (ACPA). These have also been linked to chronic air pollutants exposure, such as tobacco smoke and biomass fuel smoke. Patients with COPD and biomass exposure have higher levels of ACPA (1). Nearly $50 \%$ of the world's population still rely on biomass fuels for cooking, heating and industry, especially in low-income countries (2).

Objectives: To investigate the prevalence of biomass exposure in a cohort of Mexican-mestizo RA-subjects, and the effect of it in their RF and ACPA levels.

Methods: A cross-sectional, observational trial with RA-subjects that fulfilled the 2010 ACR/EULAR classification criteria, recruited at a rheumatology clinic in northeastern Mexico. Patient evaluation included a complete clinical history, somatometry, and blood samples to measure hs-CRP, RF isotypes (IgA, $\lg G, \lg M)$ and ACPA. Biomass exposure was documented using the biomass exposure index (BEI), defined as: average hours exposed per day multiplied by years of exposure. Descriptive analysis was done using frequencies (\%) and median values (q25-q75). Subjects were divided into 3 groups according to their $\mathrm{BEI}$ : non-exposed, $\mathrm{BEI}<30$ and $\mathrm{BEI}>30$. Comparisons were done by Chi-square and Kruskal-Wallis test and correlation by Spearman's rho test.

Results: A total of 285 subjects were included, 154 (54\%) of them had history of exposure. Comparisons are shown in Table 1. A significant difference in age was found $(p=0.006)$, this being caused by a difference between the $B E I=0$ and $B E I>30$ groups $(p<0.001)$. We also found a higher prevalence of dyslipidemia and hypertension in subjects with BEI $>30 \quad(p<0.05)$. A significant correlation between a rising $B E I$ and a higher value of ACPA (rho $=0.14, p=0.016$ ) was found; this correlation was not found with any subtype of RF ( $p>0.05)$.

Table 1. Demographic and clinical characteristics of RA according to BEI groups.

\begin{tabular}{|c|c|c|c|c|}
\hline & $\mathrm{BEI}=0$ & $\mathrm{BEI}<30$ & BEI > 30 & $\begin{array}{c}p \\
\text { value }\end{array}$ \\
\hline Age, years, median (q25-q75) & $\begin{array}{l}54(47.9- \\
59.3)\end{array}$ & $\begin{array}{c}55(49.2- \\
61.4)\end{array}$ & $\begin{array}{l}58.2(51.8- \\
\quad 65.4)\end{array}$ & NS \\
\hline Women, $n$ (\%) & $120(92.3)$ & $72(91.1)$ & $71(94.7)$ & NS \\
\hline $\begin{array}{l}\text { BEI, hours/year } \\
\text { (median, q25-q75) }\end{array}$ & $0(0-0)$ & $15(2-19)$ & $72(42-160)$ & $<0.001$ \\
\hline Dyslipidemia, n (\%) & $32(24.8)$ & $19(24.4)$ & $33(44.0)$ & 0.011 \\
\hline Type 2 diabetes, $n$ (\%) & $18(13.7)$ & $9(11.4)$ & $15(20.0)$ & NS \\
\hline Hypertension, $n(\%)$ & $32(24.4)$ & $21(26.6)$ & $33(44.0)$ & 0.007 \\
\hline $\begin{array}{l}\text { Body mass index, } \mathbf{k g} / \mathbf{m}^{2} \\
\text { median (q25-q75) }\end{array}$ & $\begin{array}{c}27.66(25.07- \\
31.6)\end{array}$ & $\begin{array}{c}27.25(24.32- \\
31.6)\end{array}$ & $\begin{array}{l}27.83(25.52- \\
31.2)\end{array}$ & NS \\
\hline $\begin{array}{l}\text { Disease Duration, years, median } \\
(q 25-q 75)\end{array}$ & $\begin{array}{c}9.03(3.4- \\
15.03)\end{array}$ & $9.5(4.01-14)$ & $\begin{array}{c}9.04(3.6- \\
15.6)\end{array}$ & NS \\
\hline DAS 28-CRP, median (q25-q75) & $3.17(1.9-4.1)$ & $3.38(2.2-4.3)$ & $\begin{array}{c}3.39(2.07- \\
4.5)\end{array}$ & NS \\
\hline Negative ACPA, $n$ (\%) & $46(38.3)$ & $20(25.3)$ & $20(27.8)$ & NS \\
\hline Group 1 ACPA, $n$ (\%) & $26(21.7)$ & $19(24.1)$ & $14(19.4)$ & NS \\
\hline Group 2 ACPA, $n$ (\%) & $31(25.8)$ & $21(26.6)$ & $18(25.0)$ & NS \\
\hline Group 3 ACPA, $n$ (\%) & $17(14.2)$ & $19(24.1)$ & $20(27.8)$ & 0.016 \\
\hline
\end{tabular}

Conclusion: In our cohort of Mexican-mestizo RA subjects, 54\% had positive biomass exposure. Subjects with a BEI $>30$ were older and had a higher prevalence of dyslipidemia and hypertension. A significant correlation was found between higher BEI index and a higher value of ACPA antibodies. 


\section{REFERENCES}

[1] Sigari N, et al. (2015). Anti-cyclic citrullinated peptide (CCP) antibody in patients with wood-smoke-induced chronic obstructive pulmonary disease (COPD) without rheumatoid arthritis. Rheumatology International.

[2] Yang, DH, et al. (2014). Circulating anti-cyclic citrullinated peptide antibody in patients with rheumatoid arthritis and chronic obstructive pulmonary disease. Rheumatology International.

Disclosure of Interests: None declared

DOI: 10.1136/annrheumdis-2019-eular.6122

\section{AB0323 CARDIOVASCULAR RISK ESTIMATION IN PATIENTS WITH RHEUMATOID ARTHRITIS TREATED WITH BIOLOGICS OR C-DMARDS}

Evangelia Mole ${ }^{1}$, Sousana Gazi ${ }^{1}$, Dimitra Moschou ${ }^{1}$, Georgia Mpaili ${ }^{1}$, Stavros Theodorakopoulos ${ }^{1}$, Konstantina Zoupidou', Nikolaos Kontodimopoulos ${ }^{2}$. " "KAT" General Hospital of Attica, Department of Rheumatology, Athens, Greece; 2"KAT" General Hospital of Attica, Division of Management, Athens, Greece

Background: Patients with Rheumatoid Arthritis (RA) are at increased risk of developing atherosclerotic cardiovascular (CV) disease. The impact of treatment with conventional or biological disease modifying drugs (c- or b-DMARDs) on inflammation of systemic circulation is an important question.

Objectives: The aim of this study is to determine the influence of therapy (c-DMARDs or b-DMARDs) on 10 year CV risk in patients with RA, over a period of 18 months.

Methods: A single center, observational study of 229 consecutive RA patients, who were treated with c-DMARDs or b-DMARDs mono/combination therapy for at least 18 months. The 10 year CV risk was calculated with Framingham risk score (FRS)

Results: A total of 229 patients were included, 111 received b-DMARDs and 194 c-DMARDs. The mean age was comparable between 2 groups $(62.45 \pm 12.74$ vs $64.56 \pm 12.48$ years, p: 0.1596$)$ and $148(64.63 \%)$ were female. Patients receiving b-DMARDs had longer disease duration compared to c-DMARDs group $(14.34 \pm 9.89$ vs $9.99 \pm 9.3$ years respectively, $\mathrm{p}$ : $0.001)$ and comparable baseline FRS 10-year percent CV risk (10.74 \pm 8.88 vs $11.68 \pm 8.78$ respectively, $\mathrm{p}: 0.3710$ ). Baseline patient distribution across intermediate $(9.6 \%$ vs $16.6 \%$ ) and high (10.91\% vs $16.16 \%)$ FRS 10 -year CV risk categories was comparable between treatment groups (bDMARDs vs c-DMARDs, p: 0.208), except low FRS category $(27.51 \%$ vs $51.53 \%$ respectively, $\mathrm{p}<0.001)$. At month 18 , FRS 10 -year CV risk category remained stable in b-DMARDs patients (low: 31.88\%, intermediate: $10.92 \%$, high: $5.24 \%$, p: 0.47 ), whereas a significant shift in FRS 10-year CV risk category was observed in c-DMARDs patients (low: $58.1 \%$, intermediate: $17.03 \%$, high: $9.17 \%$, p: 0.001). Within-group the mean (SD) change in FRS 10-year percent CV risk from baseline to month 18 was statistically significant for both b-DMARDs $(\Delta: 10.74-8.94=1.8$ (1.14), $\mathrm{p}<0.001)$ and $\mathrm{c}-\mathrm{DMARDs}(\Delta: 11.68-8.73=2.95$ (0.91), $\mathrm{p}<0.001)$.

Conclusion: Patients treated with b-DMARDs had lower baseline and month 18 10-year CV risk. However, both treatment arms induced significant improvement of 10 -year $\mathrm{CV}$ risk at 18 months.

\section{REFERENCES}

[1] Ann M. Chodara, MD, Aimée Wattiaux, BS, and Christie M. Bartels, MD, MS. Managing cardiovascular disease risk in rheumatoid arthritis: clinical updates and three strategic approaches. Curr Rheumatol Rep. 2017 Apr; 19(4): 16.

[2] Meyer PW1, Anderson R2, Ker JA3, Ally MT4. Rheumatoid arthritis and risk of cardiovascular disease. Cardiovasc J Afr. 2018 Sep/Oct 23;29 (5):317-321.

Disclosure of Interests: None declared DOI: 10.1136/annrheumdis-2019-eular.2504

\section{$\mathrm{AB} 0324$ \\ PAIN IMPROVEMENT IN RHEUMATOID ARTHRITIS PATIENTS TREATED WITH BARICITINIB: RESULTS OF A PROSPECTIVE STUDY}

Ricardo Juan Gil Velez ${ }^{1}$, Clara Aguilera Cros $^{1}$, Alberto Ruiz Roman ${ }^{1}$, Lara Mendez Diaz ${ }^{1}$, Elena Alonso Morales ${ }^{1}$, Esteban Rubio Romero ${ }^{1}$, Juan Povedano Gomez'. ' ${ }^{1}$ Seville, Seville, Spain:

Background: Assessment of pain improvement during treatment for Rheumatoid Arthritis (RA) may be useful to clinical decision between providers and their patients (pts)
Baricitinib (BARI) once daily, an oral, selective Janus Kinase (JAK)1/JAK2 inhibitor, reduced disease activity levels in Rheumatoid Arthritis (RA) patients (pts) with an inadequate response (IR) to methotrexate (MTX).

Objectives: To Evaluate the likelihood of achieving different levels of pain control with BARI $2 \mathrm{mg}$ or $4 \mathrm{mg}$ in patients with RA with inadequate response to traditional DMARDs or biological DMARDs.

Methods: Prospective observational registry of pts with RA who start treatment with BARI, in a third level Spanish Hospital (October 2017- June 2018). BARI 2 $\mathrm{mg}$ is started in patients with inadequate response to traditional DMARDs and BARI $4 \mathrm{mg}$ in patients with inadequate response to biological DMARDs. The pts were assessment of pain was assessed with $0-100 \mathrm{~mm}$ visual analog scale (VAS) at each study visit. The likelihood of achieving $>=25 \%,>=50 \%$ and $>=70 \%$ pain VAS improvement through week 12 and analyze if there are significant differences between the group of patients with BARI $2 \mathrm{mg}$ and BARI $4 \mathrm{mg}$ (Mann-Whitney test). The statistical study was carried out with the SPSS 15 computer package.

Results: We included 38 pts ( 28 women), mean age $52 \pm 12$ years Pain VAS improvement for all patients, baseline pain and weeks 12 . The frequency is the percentage of improvement with respect to the baseline. In BARI $2 \mathrm{mg}$ group, 58\% of pts (p75) have experienced a decrease greater than pain VAS improvement than baseline and in BARI $4 \mathrm{mg}$ group, $55 \%$ of pts (p75) have experienced a decrease greater than pain VAS improvement than baseline.

No statistically significant differences were found in the two treatment groups (BARI $2 \mathrm{mg}$ and BARI $4 \mathrm{mg}$ ) (p 0.847).

Conclusion: Our results, in general, agree with what is published in the literature (RA treated with BARI reported greater improvements in pain control when compared to adalimumab or placebo, a post-hoc analysis of the Phase 3 RA-BEAM study). BARI treated pts reported significantly greater and more rapid reductions in pain severity as measured by the pain VAS, improvements were sustained 12 weeks, without finding differences in pts receiving BARI $2 \mathrm{mg}$ or BARI $4 \mathrm{mg}$.

Disclosure of Interests: None declared

DOI: 10.1136/annrheumdis-2019-eular.5885

\section{AB0325 PREVALENCE OF ANXIETY/DEPRESSION IN PATIENTS WITH RHEUMATOID ARTHRITIS AT THE UNIVERSITY OF CHILE S CLINICAL HOSPITAL AND THEIR ASSOCIATIONS WITH DISSEASE ACTIVITY INDEXES AND QUALITY OF LIFE}

Anne Marie Chassin-Troubert ${ }^{1}$, Cesar Lillo ${ }^{1}$, Stephanie Prieto ${ }^{1}$, Ariel Castro ${ }^{2}$, Hector Gatica ${ }^{1}$, Pilar Carrasco ${ }^{1}$, Francisca Bozan ${ }^{1}$, Francisca Sabugo ${ }^{1}$, Pamela Wurman ${ }^{1}$, Julio Cruz ${ }^{1}$, Silvana Saavedra ${ }^{1}$, Annelise Goecke ${ }^{1} .{ }^{1}$ Hospital Clinico Universidad de Chile, Rheumatology, Santiago, Chile; ${ }^{2}$ Hospital Clinico Universidad de Chile, OAIC, Santiago, Chile

Background: Rheumatoid Arthritis is a chronic inflammatory disease with great impact in quality of life. Anxiety and depression could be frequently present in RA patients and may impact the disease activity evaluation. However psicological evaluation or therapy are not part of the standard of care of RA patients.

Objectives: To evaluate the prevalence of anxiety/depression in rheumatoid arthritis patients in control at the University of Chile's Clinical Hospital and to investigate the association of anxiety/depression with disease activity and quality of life.

Methods: The Hospital Anxiety Depression Scale (HADS) was applied to measure depression and anxiety in a cross-section patients with RA meeting the ACR/EULAR 2010 criteria in control at the University of Chile's Clinical Hospital. All patients included gave their inform consent. Demografic characteristics, Disease variables and activity, measure as DAS28-VHS, DAS-28 CRP, CDAI and SDAI and HAQ were evaluated at the same time. Spearmen correlation, Fisher exact test, Chi-Square and Kruskal-Wallis test were used according to variables at evaluation. Statistical analysis was perform by Stata v12.1 sfotware. The study was approved by the Hospital Ethic Review board.

Results: 122 patients were enrolled in the study between december 2017 and December 2018. $103(84.45 \%)$ were female. $56(46 \%)$ had depression and/or anxiety according to HADS. $24 \%$ of the patients $(n=24)$ had only depression. The severity of the depression symptoms was mild in $71 \%$, moderate in $21 \%$ and severe in $8 \%$ of the patients. $42 \%, 40 \%$ and $18 \%$ of the patients with anxiety $(n=55)$ had mild, moderate and severe anxiety symptoms respectively. The disease activity was significantly higher in patients with as compared to those without anxiety/ depression, measure with all of the following indexes: DAS28-VHS (4.33 vs $2.75, \mathrm{p}<0.001$, DAS-28 CRP ( 4.13 vs $2.75, \mathrm{p}<0.001)$, CDAl (15 vs 7 $p<0.001$ )and SDAI (17 vs $7.5, p<0.001$ ). The HAQ was also significantly higher in patients with anxiety/depression (1.18 vs $0.29, p<0.01$ 